\title{
PENGARUH SURFAKTAN TERHADAP DIAMETER PARTIKEL, VISKOSITAS DAN INDEKS POLIDISPERSITAS PADA PEMBUATAN SLN DARI LEMAK KAKAO
}

\section{EFFECT OF SURFACTANT ON PARTICLE DIAMETER, VISCOSITY AND THE POLYDISPERSITY INDEX OF SLN MAKING COCOA FAT}

\author{
Alfrida Lullung, Suprapti \\ Balai Besar Industri Hasil Perkebunan (BBIHP) \\ email : alfridalullung@yahoo.com
}

Naskah diterima 13 Agustus 2012 , disetujui 19 September 2012

\begin{abstract}
ABSTRAK
Penelitian pengaruh surfaktan terhadap diameter partikel, viskositas dan indeks polidispersitas pada pembuatan Solid Lipid Nanopartikel (SLN) dari lemak kakao. Tujuan penggunaan surfaktan (Lesitin dan sodium dodesil sulfat) dalam menghasilkan ukuran diameter partikel, viskositas dan indeks polidispersitas yang sesuai untuk pembuatan Solid Lipid Nanopartikel dari lemak kakao. Pembuatan Solid Lipid Nanopartikel dilakukan dengan menghomogenkan campuran Lemak kakao, aquades dan surfaktan (Sodium dodesil sulfat dan Lesitin) menggunakan alat Ultra Thurax, kecepatan $1500 \mathrm{rpm}$ dengan beberapa formulasi. Selanjutnya dikarakterisasi dengan alat Particle size analyzer (PSA). Hasil penelitian menunjukkan bahwa Formula Solid Lipid Nanopartikel dan surfaktan lesitin menghasilkan Indeks Polidispersitas yaitu 0.302 - 0.389 dan bersifat monomodal dibandingkan dengan surfaktan sodium dodesil sulfat dengan indeks polidispersitas lebih tinggi yaitu diatas 0.5 sebesar $0.848-1.215$ dan bersifat polimodal. Untuk diameter partikel surfaktan lesitin pada ukuran diameter partikel 426.2 - $654.3 \mathrm{~nm}$ yang sesuai dengan range diameter Solid Lipid Nanopartikel yaitu 50 - 1000 nm. Sedangkan surfaktan sodium dodesil sulfat dengan ukuran diameter partikel sebesar 2813,5 $3976,7 \mathrm{~nm}$ yang melampaui range diameter Solid Lipid Nanopartikel, viskositas pada penggunaan surfaktan lesitin sebesar 0.8980 dan 0.8878 dan surfaktan Sodium dodesil sulfat sebesar 0.8878 .
\end{abstract}

Kata Kunci : Solid Lipid Nanopartikel, Surfaktan, Indeks polidispersitas, Ukuran partikel

\section{ABSTRACT}

Study the influence of surfactants on the particle diameter, viscosity and polydispersity index of Solid Lipid Nanoparticles in manufacturing (SLN) of the cocoa butter. Intended use of surfactants (lecithin and sodium dodecyl sulfate) in generating particle diameter, viscosity and polydispersity index suitable for the manufacture of Solid Lipid Nanoparticles of cocoa butter. Preparation of Solid Lipid Nanoparticles made by homogenizing a mixture of cocoa fat, distilled water and a surfactant (sodium dodecyl sulfate, and 
lecithin) using Ultra Thurax, speed of $1500 \mathrm{rpm}$ with some formulations. Further characterized by means of Particle size analyzer (PSA). The results showed that Formula Solid Lipid Nanoparticles and surfactant lecithin produced polydispersity index is 0302-0389 and is monomodal compared to surfactant sodium dodecyl sulfate with a higher polydispersity index is above 0.5 for 0848-1215 and are polymodal. For lecithin surfactant particle diameter on particle diameter 426.2 - $654.3 \mathrm{~nm}$ corresponding to the diameter of Solid Lipid Nanoparticles range is 50-1000 $\mathrm{nm}$. While the surfactant sodium dodecyl sulfate particles with a diameter of 2813.5 to $3976.7 \mathrm{~nm}$ diameter beyond the range of Solid Lipid Nanoparticles, on the use of surfactant lecithin viscosity of 0.8980 and 0.8878 and the surfactant sodium dodecyl sulfate at 0.8878 .

Key Words : Solid Lipid Nanoparticles, Surfactants, Polydispersity index, Particle size

\section{PENDAHULUAN}

$\mathrm{P}$ artikel pembawa obat telah banyak diteliti bertahun- tahun, meliputi emulsi minyak dalam air (oil in water, OW) liposom, mikropartikel dan nanopartikel berbasis polimer sintetis maupun makromolekul alam (Muller at all, 2000). Emulsi minyak dalam air pertama kali diperkenalkan pada tahun 1950 - an untuk menghantarkan nutrisi parentaral. Berdasarkan sistem emulsi inilah formulasi emulsi minyak dalam air yang mengandung obat dikembangkan.

Solid Lipid Nanopartikel (SLN) adalah partikel dibuat dari lemak padat dengan nilai rata-rata diameter Photon Correlation Spectroscopy (PCS) kirakira $\quad 50 \quad-1000 \quad \mathrm{~nm}$. Solid Lipid Nanopartikel diperoleh dari emulsi dimana untuk nutrisi yang diasup dari luar tubuh (nutrisi parenteral) dengan menggantikan lemak cair (minyak) dalam butiran emulsi dengan lemak padat. Emulsi untuk nutrisi parenteral yang pada umumnya distabilkan dengan lesitin, sedangkan SLN dapat distabilkan dengan surfaktan lain atau polimerpolimer dalam campurannya. (Muller at all, 2000).

Lemak kakao disebut juga sebagai minyak teobroma, dimana lemak alami yang diperoleh dari nib kakao hasil pemisahan dengan proses pengempaan hidrolik atau expeller. Lemak kakao memiliki sifat khas yakni bersifat plastis dan memiliki kandungan lemak padat yang relatif tinggi. Dua karateristik lemak kakao yang penting adalah kadar asam lemak bebas serta kekerasannya (hardness). Kandungan asam lemak bebas dalam lemak kakao kurang dari 1,75 \%. Kekerasan lemak berkaitan erat dengan panjang rantai karbon dan derajat ketidakjenuhan asam lemak penyusunnya. Secara umum dapat dikatakan semakin panjang rantai karbon semakin tinggi titik cairnya sehingga lemaknya semakin keras. Demikian pula semakin rendah derajat ketidakjenuhan asam - asam lemak penyusunnya akan semakin tinggi titik cairnya sehingga lemaknya juga semakin keras. Komposisi asam lemak kakao termasuk asam lemak dengan kalori tinggi yaitu asam-asam lemak rantai panjang palmitat $(25.4 \%)$, stearat $(33.2 \%)$ dan oleat $32.6 \%$ (Ketaren, 1996)

Surfaktan merupakan senyawa aktif penurun tegangan permukaan (surface active agent). Surfaktan merupakan molekul amphipatic yang memiliki sifat hidrofilik yang bersifat polar dan hidrofobik yang bersifat non 
polar. Karena sifat ini surfaktan dapat larut dalam larutan yang berbeda derajat polaritas dan ikatan hidrogennya seperti air dan minyak. Konfigurasi hidrofilik dan hidrofobik tersebut membuat surfaktan memiliki fungsi yang beragram di berbagai industri seperti Industri farmasi, kosmetik, kimia, pertanian dan pangan. Aplikasi surfaktan dalam industri antara lain sebagai pembasah, pembentukan busa dan penstabil emulsi. Dalam polimer emulsi, surfaktan berfungsi sebagai penghasil misel untuk tempat nukleasi partikel serta berfungsi sebagai penstabil dari emulsi yang sedang terbentuk yang selanjutnya akan terdistribusi dalam polimer emulsi.

Salah satu faktor yang menentukan sifat/karakter emulsi adalah ukuran partikel dan indeks polidispersitas (Muller at all, 2000). Polimer emulsi mengandung ukuran partikel dengan diameter berkisar antara 10 sampai dengan $1.500 \mathrm{~nm}$. Polimer dengan Indeks polidisperse mempunyai ukuran partikel yang bervariasi dengan perbedaan ukuran partikel cukup besar (distribusi ukuran partikel/Indeks polidispersitas yang dihasilkan akan melebar). Sedangkan monodisperse mempunyai ukuran partikel polimer yang sama, maka distribusi ukuran partikel yang dihasilkan akan sempit

Ukuran partikel, viskositas dan indeks polidispersitas sangat menentukan sifat emulsi seperti sifat kestabilan. Dalam industri ukuran partikel, viskositas dan indeks polidispersitas adalah sangat penting dan berhubungan dengan sifat fisika dan stabilisasi emulsi. Stabilisasi sistem emulsi atau dispersi akan berkurang dengan kenaikan ukuran partikel dan distribusinya. Snuparek et al, (1984) menjelaskan bahwa, salah satu faktor yang sangat mempengaruhi Indeks Polidispersitas, viskositas dan ukuran diameter Partikel adalah penggunaan surfaktan.
Lemak kakao telah lama digunakan sebagai eksipien untuk penggunaan secara suppositorial (Lowenthal, W. and Borzelleca, J. F., 1965; Khan A.M, et al., 2000), karena sifatnya yang meleleh pada suhu tubuh manusia. Tetapi penggunaan lemak kakao sebagai material pembawa obat, baru berkembang sekitar sepuluh tahun terkahir. Jenning, Thunemann dan Gohla pada tahun 2000 melaporkan pembuatan material pembawa nanopartikel lemak padat system biner, yaitu dengan menggabungkan lemak kakao dengan minyak sebagai inti padatnya. Nanopartikel ini dilaporkan sesuai untuk penggunaan secara topikal (Jenning, Thunemann and Gohla, 2000). Penelitian mengenai pembuatan lemak kakao sebagai bahan baku nanopartikel lemak padat telah dilakukan oleh Kim, $\mathrm{Na}$ dan Choi pada tahun 2005. Lemak kakao sebagai inti dari nanopartikel lemak padat sedangkan dadih (curdlan) sebagai lapisan kulit (penyalut) dari nanaopartikel lemak padat (Kim, $\mathrm{Na}$ and Choi, 2005) . Namun demikian, stabilitas nanopartikel lemak padat yang dihasilkan dari lemak kakao banyak dipengaruhi oleh adanya bentuk polimorfis kristal $(\alpha, \beta, \gamma)$ dari lemak kakao, sehingga selalu menjadi permasalahan yang harus selalu diperhatikan dalam setiap penelitian. Untuk itu dilakukan penelitian pengaruh surfaktan terhadap Indeks polidispersitas, Viskositas dan ukuran diameter Partikel pada pembuatan Solid Lipid Nanopartikel dari lemak kakao yang bertujuan untuk mengetahui penggunaan surfaktan (Lesitin dan sodium dodesil sulfat) dalam menghasilkan diameter partikel, viskositas dan indeks polidispersitas yang sesuai untuk pembuatan Solid Lipid Nanopartikel dari lemak kakao. 


\section{METODE PENELITIAN}

\section{Bahan dan Alat}

Bahan yang digunakan dalam penelitian ini antara lain lemak kakao yang di peroleh dari hasil pengepresan/pengempaan biji kakao yang berasal dari Kab. Luwu dengan kadar asam lemak bebas < $1 \%$ ), sodium dodesil sulfat, lesitin cair dan aquadest.

Alat yang digunakan dalam penelitian ini antara lain gelas piala, neraca analitik, ultra thurrax, penangas air dan particle size analyzer untuk analisa Indeks Polidispersitas, Viskositas dan diameter partikel.

\section{Metode}

Penelitian ini dilakukan di laboratorium Sekolah Farmasi Institut Teknologi Bandung (ITB) Bandung. Metode yang digunakan adalah lemak kakao dilelehkan di atas penangas pada suhu $37{ }^{\circ} \mathrm{C}$. Setelah lemak kakao meleleh, ditambahkan surfaktan (lesitin dan sodium dodesil sulfat) yang telah dicampur dengan aquades dan diaduk dengan alat ultra thurrax dengan kecepatan $16.000 \mathrm{rpm}$ selama 10 menit dengan beberapa formulasi/perlakuan. Solid Lipid Nanopartikel (SLN) yang dihasilkan selanjutnya dikarakterisasi melalui analisa Indeks polidispersitas, Viskositas dan ukuran diameter partikel dilakukan dengan menggunakan alat particle size analyzer (PSA).

Tabel 1 : Formula Pembuatan Solid Lipid Nanopartikel (SLN) dari Lemak Kakao

\begin{tabular}{|c|c|c|}
\hline \multicolumn{3}{|c|}{ Formula } \\
\hline \multirow{3}{*}{ I. } & Lemak Kakao & $5 \mathrm{~g}$ \\
\hline & Sodium Dodesil Sulfat & $0.5 \mathrm{~g}$ \\
\hline & Air & $94.5 \mathrm{~g}$ \\
\hline \multirow{3}{*}{ II. } & Lemak Kakao & $10 \mathrm{~g}$ \\
\hline & Sodium Dodesil Sulfat & $1 \mathrm{~g}$ \\
\hline & Air & $89 \mathrm{~g}$ \\
\hline \multirow{3}{*}{ III. } & Lemak Kakao & $5 \mathrm{~g}$ \\
\hline & Lesitin & $2 \mathrm{~g}$ \\
\hline & Air & $83 \mathrm{~g}$ \\
\hline \multirow{3}{*}{ IV. } & Lemak Kakao & $10 \mathrm{~g}$ \\
\hline & Lesitin & $4 \mathrm{~g}$ \\
\hline & Air & $86 \mathrm{~g}$ \\
\hline
\end{tabular}

\section{HASIL DAN PEMBAHASAN}

\section{Indeks Polidispersitas}

Indeks Polidispersitasnya menunjukkan distribusi ukuran partikel suatu polimer emulsi, apabila emulsi yang dihasilkan mempunyai indeks Polidispersitas yang rendah maka bersifat monomodal (monodisperse), sedangkan jika indeks Polidispersitas tinggi maka bersifat polimodal (polidisperse). Emulsi dapat dikatakan monomodal jika indeks polidispersitasnya di bawah 0,1 sedangkan jika indeks polidispersitasnya berada di atas 0.5 maka dapat dikatakan bersifat polimodal. Nilai indeks polidispersitas yang berada antara $0.1-0.5$ harus 
dianalisis terlebih dahulu berdasarkan puncak - puncak kromatogram yang diperoleh. Semakin lebar peak yang didapat maka molekul polimer yang terbentuk semakin tidak seragram, sebaliknya semakin tinggi dan sempit peak yang diperoleh, maka polimer yang terbentuk semakin monodispers (Kurnia Syah Putri, 2008). Formula Solid Lipid Nanopartikel dari lemak kakao didasarkan pada prinsip emulsifikasi. Hasil uji Indeks Polidispersitas dari proses Pembuatan Solid Lipid Nanopartikel (SLN) dengan menggunakan lemak kakao pada berbagai konsentrasi surfaktan sodium dodesil sulfat dan lesitin yang diperoleh menggunakan alat particle size analyzer (PSA), dapat dilihat pada Tabel 2.

Tabel 2. Indeks Polidispersitas pada Berbagai Formula SLN

\begin{tabular}{|c|c|c|c|}
\hline \multicolumn{3}{|c|}{ Formula } & $\begin{array}{c}\text { Indeks } \\
\text { Polidispersitas }\end{array}$ \\
\hline \multirow{3}{*}{ I. } & Lemak Kakao & $5 \mathrm{~g}$ & \multirow{3}{*}{1.215} \\
\hline & Sodium Dodesil Sulfat & $0.5 \mathrm{~g}$ & \\
\hline & Air & $94.5 \mathrm{~g}$ & \\
\hline \multirow{3}{*}{ II. } & Lemak Kakao & $10 \mathrm{~g}$ & \multirow{3}{*}{0.848} \\
\hline & Sodium Dodesil Sulfat & $1 \mathrm{~g}$ & \\
\hline & Air & $89 \mathrm{~g}$ & \\
\hline \multirow{3}{*}{ III. } & Lemak Kakao & $5 \mathrm{~g}$ & \multirow{3}{*}{0.339} \\
\hline & Lesitin & $2 \mathrm{~g}$ & \\
\hline & Air & $83 \mathrm{~g}$ & \\
\hline \multirow{3}{*}{ IV. } & Lemak Kakao & $10 \mathrm{~g}$ & \multirow{3}{*}{0.302} \\
\hline & Lesitin & $4 \mathrm{~g}$ & \\
\hline & Air & $86 \mathrm{~g}$ & \\
\hline
\end{tabular}

Berdasarkan Tabel 2 dapat dilihat bahwa Solid Lipid Nanopartikel yang dihasilkan dengan menggunakan surfaktan lesitin pada campuran 5 gram lemak kakao, air 83 gram dan 2 gram lesitin dan campuran 10 gram lemak kakao, air 86 gram dan 4 gram lesitin keduanya menghasilkan indeks polidispersitas sebesar 0.302 dan 0.339 , sedangkan pada penggunaan surfaktan Sodium Dodesil Sulfat pada formula 5 gram lemak kakao, air 94.5 dan 0,5 gram Sodium dodesil sulaf dan formula 10 gram lemak kakao, air 89 gram dan 1 gram sodium dodesil sulfat menghasilkan indeks polidispersitas masing - masing 0.848 dan 1.215. Hal ini menunjukkan bahwa semakin kecil konsentrasi dari surfaktan lesitin dan sodium dodesil sulfat yang ditambahkan, semakin besar indeks polidispersitas yang dihasilkan sehingga campuran yang terbentuk lebih bersifat polidispers, hal ini sesuai dengan pendapat yang diungkapkan Capek (2000) yang menyatakan bahwa semakin kecil konsentrasi surfaktan yang digunakan maka campuran yang terbentuk semakin bersifat polidispers atau polidispersitasnya semakin besar. Terjadinya peningkatan nilai polidispersitas tersebut dikarenakan pada kondisi tersebut jumlah surfaktan yang ditambahkan sangat sedikit menyebabkan inti partikel polimer yang terbentuk berukuran besar kemudian inti partikel polimer tersebut berpolimerisasi menjadi polimer yang lebih besar, namun ukuran partikel polimer yang terlalu besar tidak dapat distabilkan oleh surfaktan sehingga partikel polimer pecah menjadi polimer yang berukuran sangat kecil yang dinamakan git. Adanya git 
menyebabkan distribusi ukuran partikel polimer menjadi tidak merata (polidispers). Sehingga indeks polidispersitasnya menjadi lebih besar.

Dilihat dari indeks

polidispersitasnya maka emulsi yang paling monodispers dihasilkan pada pembuatan SLN dengan menggunakan surfaktan lesitin yaitu dengan indeks polidispersitas 0,302 dan 0, 339 . Sedangkan pada pembuatan SLN dengan menggunakan surfaktan sodium

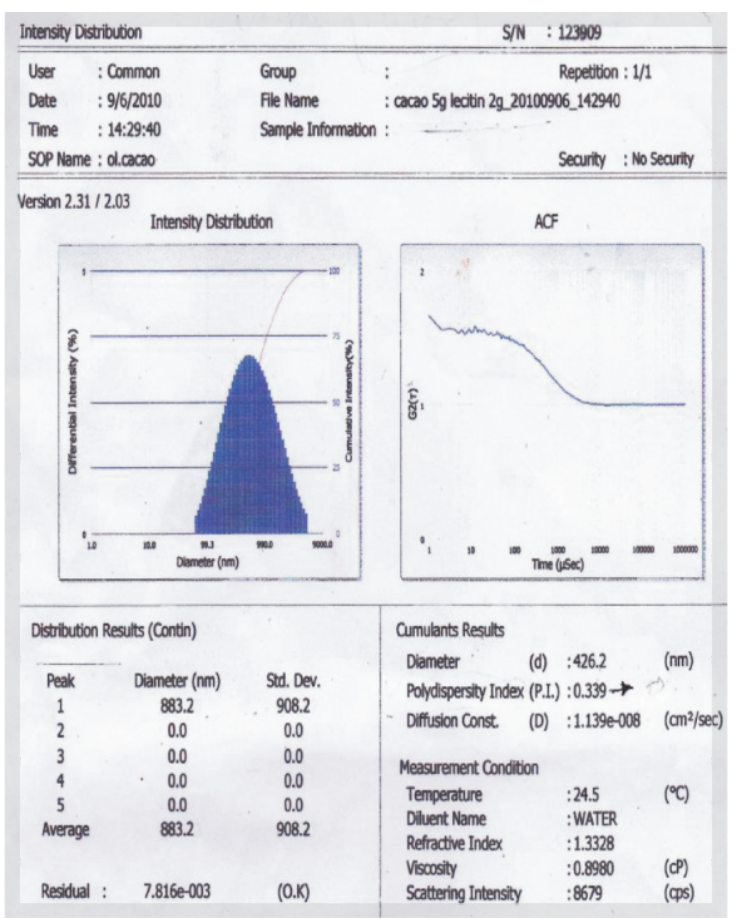

dodesil sulfat emulsi yang dihasilkan lebih bersifat polidispers dengan indeks polidispersitas 0.848 dan 1.215. dan berdasarkan diameter peak, pada penggunaan surfaktan lesitin (gambar 1) diameter peak 883,2 dan 1196 lebih sempit dibandingkan pada penggunaan surfaktan sodium dodesil sulfat diameter 21321 dan 11005,8 lebih lebar, diameter peak yang lebar menunjukkan polimer yang terbentuk semakin tidak beraturan (polidispers).

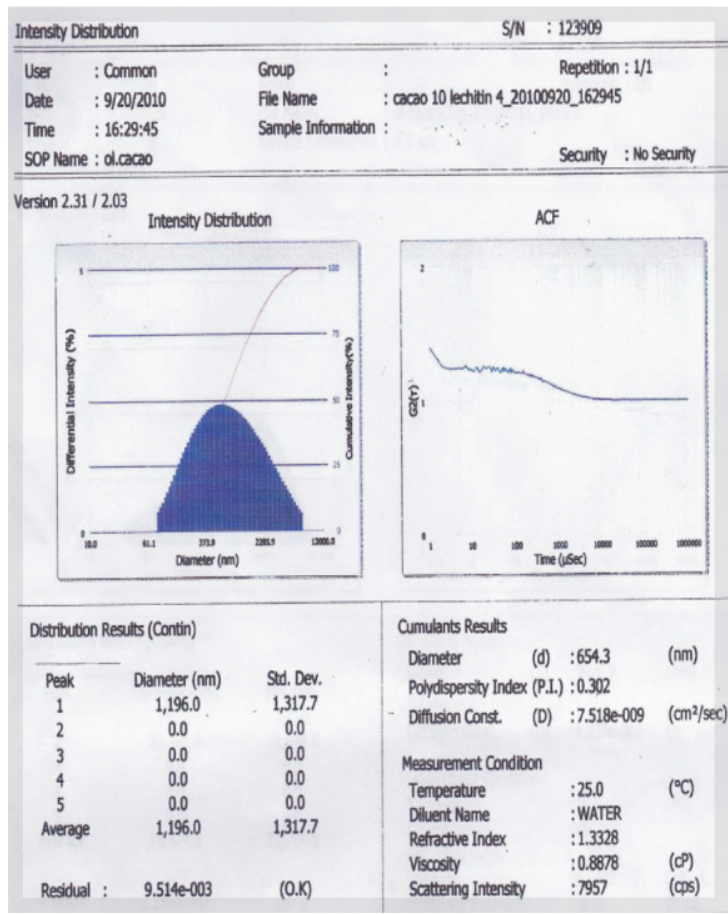

(a) 


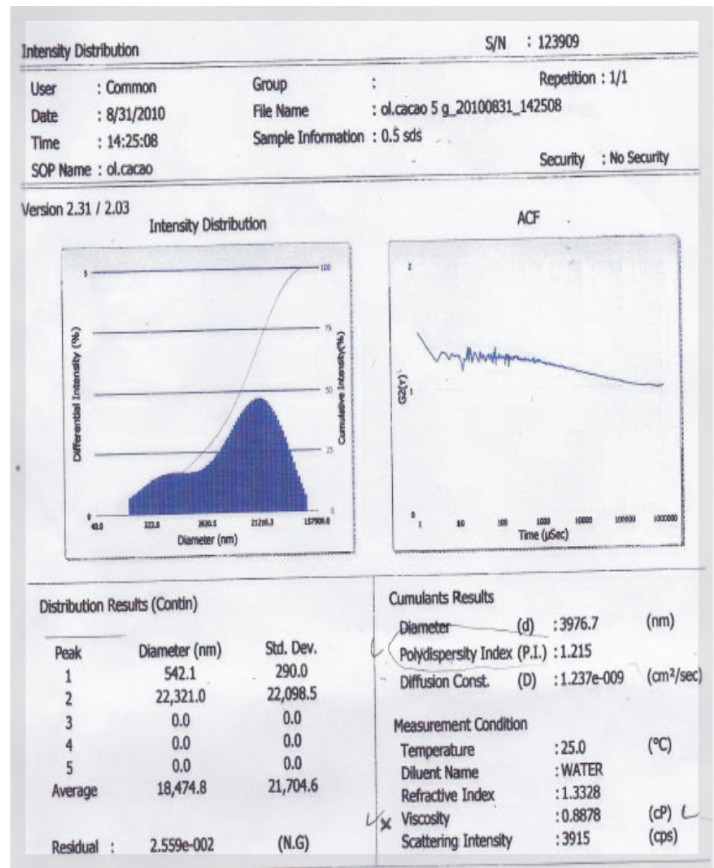

(b)

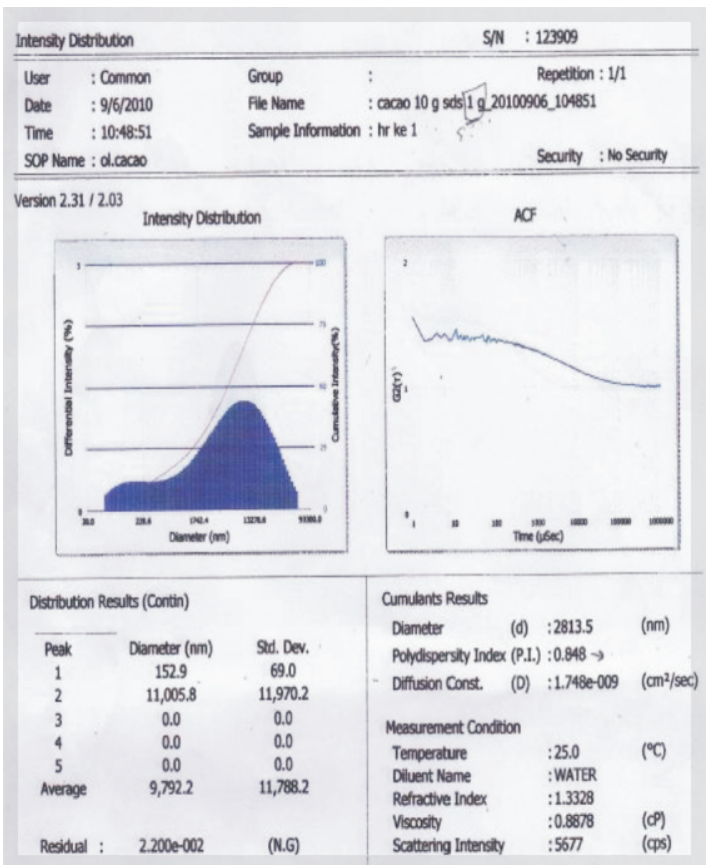

Gambar 1 : Hasil Kromatogafi Surfaktan Lesitin (a) dan Surfaktan Sodium Dodesil Sulfat (b)

\section{Diameter Partikel}

Diameter partikel memiliki peranan yang sangat besar dalam pembuatan material pembawa obat Solid Lipid Nanopartikel. Menurut Rainer at all (2006) nilai rata-rata diameter Photon Correlation Spectroscopy (PCS) material pembawa obat Solid Lipid Nanopartikel (SLN) kira-kira 50-1000 $\mathrm{nm}$. Pada variasi ini dipelajari pengaruh konsentrasi surfaktan lesitin dan sodium dodesil sulfat terhadap ukuran diameter partikel. Hasil yang diperoleh dapat dilihat pada Tabel 3.

Tabel 3. Diameter Partikel pada Berbagai Formula SLN

\begin{tabular}{|c|c|c|c|}
\hline \multicolumn{3}{|c|}{ Formula } & Diameter Partikel (nm) \\
\hline \multirow{3}{*}{$\mathrm{I}}$. & Lemak Kakao & $5 \mathrm{~g}$ & \multirow{3}{*}{3976,7} \\
\hline & Sodium Dodesil Sulfat & $0.5 \mathrm{~g}$ & \\
\hline & Air & $94.5 \mathrm{~g}$ & \\
\hline \multirow{3}{*}{ II. } & Lemak Kakao & $10 \mathrm{~g}$ & \multirow{3}{*}{2813,5} \\
\hline & Sodium Dodesil Sulfat & $1 \mathrm{~g}$ & \\
\hline & Air & $89 \mathrm{~g}$ & \\
\hline \multirow{3}{*}{ III. } & Lemak Kakao & $5 \mathrm{~g}$ & \multirow{3}{*}{426,2} \\
\hline & Lesitin & $2 \mathrm{~g}$ & \\
\hline & Air & $83 \mathrm{~g}$ & \\
\hline \multirow{3}{*}{ IV. } & Lemak Kakao & $10 \mathrm{~g}$ & \multirow{3}{*}{654,3} \\
\hline & Lesitin & $4 \mathrm{~g}$ & \\
\hline & Air & $86 \mathrm{~g}$ & \\
\hline
\end{tabular}


Berdasarkan Tabel 3 di atas diperoleh data bahwa kenaikan konsentrasi surfaktan sodium dodesil sulfat menghasilkan ukuran partikel yang lebih kecil. Hal ini sesuai dengan yang dikemukakan Smith dan Ewart (1998) yang menyatakan bahwa konsentrasi surfaktan yang digunakan sebanding dengan jumlah partikel yang dihasilkan sehingga semakin tinggi konsentrasi yang digunakan maka semakin banyak jumlah partikel yang dihasilkan. Sebagai konsekuensinya ukuran diameter partikel yang dihasilkan akan semakin kecil. Surfaktan mempunyai peran penting dalam penentuan ukuran partikel. Hal ini dikarenakan ketika dilarutkan dalam media air, surfaktan akan beragegat membentuk misel yang akan menjadi tempat terjadinya polimerisasi dan menentukan ukuran partikel yang dihasilkan. Fenomena ini terjadi karena semakin banyak konsentrasi surfaktan yang digunakan maka akan semakin banyak misel yang dihasilkan, sehingga banyak senyawa-senyawa yang akan berpolimerisasi terdistribusi ke sejumlah misel tersebut, dengan demikian akan sedikit senyawa yang akan bereaksi akibatnya ukuran partikel yang dihasilkan akan lebih kecil dibandingkan dengan konsentrasi surfaktan yang rendah, seperti pada formula pembuatan SLN menggunakan surfaktan Sodium dodesil sulfat 5 gram lemak kakao, air 94.5 dan 0,5 gram Sodium dodesil sulfat ukuran partikel yang dihasilkan sebesar 3976.7.

Pada konsentrasi ini misel yang dihasilkan dalam jumlah yang sedikit sehingga jumlah senyawa - senyawa yang terdistribusi kedalam misel akan lebih banyak akibatnya ukuran partikel

Viskositas dari Pembuatan SLN dengan menggunakan lemak kakao pada berbagai konsentrasi surfaktan yang dihasilkan akan lebih besar dibandingkan pada formula pembuatan SLN dengan surfaktan sodium dodesil sulfat 1 gram, air 89 gram dan lemak kakao 10 gram ukuran partikel yang dihasilkan sebesar 2813,5. Berbeda pada penggunaan surfaktan lesitin ukuran partikel yang dihasilkan pada formula lesitin $10 \mathrm{~g}$ lemak kakao, air 86 g dan 4 gram lesitin sebesar 654,3 lebih besar dibandingkan dengan ukuran partikel yang dihasilkan pada formula 5 gram lemak kakao, air 83 gram dan 2 gram lesitin sebesar 426,2 . Besarnya ukuran partikel pada formula lesitin 4 gram lesitin, air 86 dan 10 gram lemak kakao sebesar 654.3 disebabkan oleh timbulnya misel inaktif di dalam sistem emulsi. Menurut Justika (2008), di dalam sistem emulsi terdapat tiga jenis partikel yaitu senyawa droplet, misel inaktif yang tidak terjadi polimerisasi di dalamnya dan misel aktif yang terjadi polimerisasi di dalamnya. Misel inaktif tidak mengandung senyawa di dalam intinya. Oleh karena itu dengan sendirinya ukuran misel inaktif akan jauh lebih kecil dibandingkan misel aktif. Hal itu akan memberi ruang bagi misel aktif untuk dapat lebih mengembangkan dirinya hingga batas maksimum dari kapasitasnya sehingga jumlah senyawa monomer yang masuk kedalam misel akan jauh lebih banyak sehingga ukuran partikel menjadi lebih besar.

\section{Viskositas}

Viskositas pada polimer emulsi menunjukkan kekentalan dan kemampuan emulsi dalam mengalir. Sifat alir ini merupakan salah satu parameter penting pada polimer emulsi.

sodium dodesil sulfat dan lesitin diperoleh menggunakan alat particle size analyzer (PSA), dapat dilihat pada Tabel 4. 
Tabel 4. Viskositas pada Berbagai Formula SLN

\begin{tabular}{|c|c|c|c|}
\hline \multicolumn{3}{|c|}{ Formula } & $\begin{array}{c}\text { Viskositas } \\
\text { (mPas) }\end{array}$ \\
\hline \multirow{3}{*}{ I. } & Lemak Kakao & $5 \mathrm{~g}$ & \multirow{3}{*}{0.8878} \\
\hline & Sodium Dodesil Sulfat & $0.5 \mathrm{~g}$ & \\
\hline & Air & $94.5 \mathrm{~g}$ & \\
\hline \multirow{3}{*}{ II. } & Lemak Kakao & $10 \mathrm{~g}$ & \multirow{3}{*}{0.8878} \\
\hline & Sodium Dodesil Sulfat & $1 \mathrm{~g}$ & \\
\hline & Air & $89 \mathrm{~g}$ & \\
\hline \multirow{3}{*}{ III. } & Lemak Kakao & $5 \mathrm{~g}$ & \multirow{3}{*}{0.8980} \\
\hline & Lesitin & $2 \mathrm{~g}$ & \\
\hline & Air & $83 \mathrm{~g}$ & \\
\hline \multirow{3}{*}{ IV. } & Lemak Kakao & $10 \mathrm{~g}$ & \multirow{3}{*}{0.8878} \\
\hline & Lesitin & $4 \mathrm{~g}$ & \\
\hline & Air & $86 \mathrm{~g}$ & \\
\hline
\end{tabular}

Hasil pengukuran viskositas yang tertera pada Tabel 4 menunjukkan bahwa dengan semakin tinggi/meningkatnya konsentrasi surfaktan maka viskositas akan semakin menurun. Walaupun perubahan yang terjadi tidak terlalu signifikan, hasil ini sesuai yang dikemukakan Smith dan Ewart (1998) bahwa semakin tinggi konsentrasi surfaktan yang digunakan maka semakin banyak jumlah partikel yang dihasilkan dan ukuran partikel yang dihasilkan akan semakin kecil. Sehingga viskositas larutan pun akan semakin rendah. Viskositas berhubungan juga dengan distribusi ukuran partikel. Semakin monodispers suatu partikel, maka viskositasnya akan semakin besar, karena jarak antara partikel semakin dekat sehingga interaksi yang terjadi semakin kuat. Hal ini sesuai dengan yang diungkapkan Scheider (2002), bahwa viskositas akan rendah jika partikel mempunyai ukuran yang polimodal dibandingkan dengan monomodal.

\section{KESIMPULAN}

Formula Solid Lipid Nanopartikel yang menggunakan surfaktan lesitin menghasilkan Indeks Polidispersitas di bawah nilai 0.5 dan bersifat monomodal yaitu $0.302-0.389$ sedang surfaktan sodium dodesil sulfat dengan indeks polidispersitas lebih tinggi yaitu diatas 0.5 yaitu $0.848-1.215$ dan bersifat polimodal. Penggunaan surfaktan lesitin menghasilkan ukuran diameter partikel 426.2 - $654.3 \mathrm{~nm}$ yang sesuai dengan rentang diameter Solid Lipid Nanopartikel yaitu $50-1000 \mathrm{~nm}$ sedangkan surfaktan sodium dodesil sulfat menghasilkan ukuran diameter partikel sebesar 2813,5 - 3976,7 nm yang melampaui range diameter Solid Lipid Nanopartikel serta untuk viskositas pada penggunaan surfaktan lesitin sebesar 0.8980 dan 0.8878 dan surfaktan Sodium dodesil sulfat sebesar 0.8878. Penelitian masih perlu dikembangkan dengan penggunaan surfaktan yang lain dengan konsentrasi surfaktan yang lebih bervariasi.

\section{DAFTAR PUSTAKA}

Capek, 2006. Emulsion Polymerization Mechanisms and Kinetics, Department of Chemical Engineering, National Taiwan University of Science and Technology 
Jenning, V., Thunemann, A. F., Gohla, S. H.,2000, Characterisation of $A$ Novel Solid Lipid Nanoparticle Carrier System Based on Binary Mixtures of Liquid and Solid Lipids, International J. of pharmaceutical Sci. 199 (2)

J. Snuparek, Z. Kleckova, J. 1984. Colloidal and film properties of carboxylated acrylic latices - effect of surfactant concentration", Pigment \& Resin Technology, Vol. 27 Iss: 1, pp.20 - 27 J. Appl. Polym.Sci. 29

Kim, B.D., Na, K., Choi, H. K., 2005, Preparation and Character isat ion of Solid Lipid Nanoparticle Made of Cocoa Butter,European J. of pharmaceutical Sci, 24 (2)

Kurnia syah Putri, 2008. Studi Optimasi Polimerisasi Metil Metakrilat ; Pengaruh Variasi Konsentrasi Inisiator Amonium Persulfat Monomer Metil Metakrilat dan surfaktan natrium lauril sulfat terhadap ukuran dan distribusi ukuran partikel.(tesis) Departemen Kimia, FMIPA, Universitas Indonesia, Indonesia..
Ketaren, S. 1996. Pengantar Teknologi lemak dan Minyak Pangan. UI Press. Jakarta, 315 p.

Lowenthal, W., Borzelleca, J. F., 1965, Drug Absorption from The Rectum I. Suppository

Bases : A Preliminary Report, J. of pharmaceutical Sci. 54 (12)

Muller, R. H., Mader, K., Gohla, S., 2000, Solid Lipid Nanoparticle (SLN) for Controlled Drug Delivery - A Review of The State of The Art, European J. of pharmaceutical and Biopharmaceutics ,50, pp. 161177

Schneider, M., C. Gaillat, A.Guyot T.F. (2002 McKenna, "High Solids Content Emulsions. J. Appl. Polym. Sci., 84(10), 1897-1915).

W.V. Smith and Ewart, Journal chemical physics, Kinetics of Emulsion Polymerization Vo. $16 /$ issue 6 J. Chem. Phys. 16, 592 (1998); 